\title{
Evaluation of a PCR-immunoassay technique for detection of Neisseria meningitidis in cerebrospinal fluid and peripheral blood
}

\author{
R. J. SEWARD and K. J. TOWNER
}

Department of Microbiology and PHLS Laboratory, University Hospital, Queen's Medical Centre, Nottingham NG7 $2 U H$

\begin{abstract}
A multiplex PCR-immunoassay for the rapid diagnosis of bacterial meningitis from cerebrospinal fluid (CSF) or peripheral blood was compared with conventional microbiological techniques used in the routine diagnostic laboratory. The multiplex PCR was designed to detect simultaneously a universal conserved sequence coding for bacterial 16S rRNA and the Neisseria meningitidis porA gene. The PCR-immunoassay had a detection limit of $(3-5) \times 10^{2} \mathrm{cfu} / \mathrm{ml}$ (equivalent to $1-3 \mathrm{cfu} / \mathrm{PCR}$ ) with spiked CSF or blood samples, compared with $(3-5) \times 10^{3} \mathrm{cfu} / \mathrm{ml}$ for PCR followed by conventional agarose gel electrophoresis for detection of PCR products. Of 294 CSF samples from patients suspected on clinical grounds of suffering from meningitis, the PCR-immunoassay detected bacterial DNA in 29 CSF samples, 15 of which were also positive for $N$. meningitidis DNA. The 29 positive CSF samples comprised 25 samples that were also reported positive and four that were reported negative by conventional methodology; the latter four were all positive for $N$. meningitidis by the PCRimmunoassay. Of 173 peripheral blood samples examined, the PCR-immunoassay detected bacterial DNA in 18 samples, 14 of which were also positive for $N$. meningitidis DNA. In comparison, only 10 samples were reported positive for $N$. meningitidis by conventional methodology. All negative PCR-immunoassay results correlated with those obtained by conventional methodology for both CSF and blood samples. The sensitivity and speed of the PCR-immunoassay system indicated that it could be used as a routine diagnostic test for meningococcal meningitis, enabling a diagnosis to be made within $4 \mathrm{~h}$ of receipt of the specimen.
\end{abstract}

\section{Introduction}

Meningococcal disease remains an important health problem in the UK and world-wide. Rapid detection and identification of bacterial pathogens in cases of suspected meningitis are important in guiding appropriate treatment and prophylaxis. However, confirmation of a diagnosis of bacterial meningitis is often difficult. An initial presumptive diagnosis is normally made on the basis of clinical observations and this is then supported by microscopic examination of cerebrospinal fluid (CSF) for gram-negative diplococci and culture of the infecting organism from CSF or blood. Confirmation of the diagnosis can be made from CSF in almost $90 \%$ of patients [1], but it may be difficult to obtain a sample of CSF, particularly from young

Received 18 Aug. 1999; accepted 18 Oct. 1999.

Corresponding author: Dr K. J. Towner (e-mail: Kevin. Towner@nottingham.ac.uk). infants, and lumbar puncture is sometimes contraindicated because of raised intracranial pressure [2]. Meningococci can be cultured from blood in c. 50\% of untreated patients [3], but pre-admission antibiotic treatment, which reduces mortality and is recommended by the Chief Medical Officers in the UK, reduces the chance of a positive blood culture to $\leqslant 5 \%$ [4]. Nevertheless, confirmation of diagnosis remains essential for: (i) optimum treatment of the patient; (ii) informed counselling of contacts, particularly when clusters of suspected cases occur, e.g., in a school or university; and (iii) monitoring the efficiency of and need for immunisation.

In response to this need, a number of different techniques based on the PCR have been developed to detect bacterial pathogens in cases of suspected meningitis [e.g., 3,5-8]. Successful application of PCR does not depend on the presence of viable organisms and, consequently, the PCR technique is now 
used routinely by the PHLS Meningococcal Reference Unit in the UK to investigate presumed cases of bacterial meningitis [9]. Specific meningococcal PCR products are normally detected following agarose gel electrophoresis or in enzyme-linked immunosorbent assays (ELISAs) [3]. However, the requirement for relatively time-consuming and technically demanding DNA extraction and detection procedures [3] has limited the introduction of this successful technique into routine diagnostic laboratories.

In an attempt to widen the scope for the introduction of these successful tests, the present work evaluated a multiplex PCR for detection of bacterial meningitis in combination with simplified DNA extraction procedures and a user-friendly immunoassay device that recognises PCR products rapidly and specifically within 5 min of completion of the PCR. A positive result is recognised by the appearance of a simple-to-read blue line in the immunoassay device. Thus the electrophoresis or ELISA steps are no longer necessary and the entire test, yielding a specific diagnosis of meningococcal meningitis, is complete within $4 \mathrm{~h}$ of specimen receipt (i.e., at least $20 \mathrm{~h}$ quicker than conventional microbiological culture methods). The PCR-immunoassay devices have already been used (with different primer sets) for the detection of methicillin-resistant Staphylococcus aureus (MRSA) strains [10] and specific antibiotic resistance genes in clinical isolates [11], and have been shown to have enhanced sensitivity compared with the detection of PCR products by gel electrophoresis.

\section{Materials and methods}

\section{Bacteria and clinical samples}

A suspension of Neisseria meningitidis strain SD, B:15:P1 was prepared by emulsifying a small loopful of overnight growth, taken from the surface of a blood agar plate, in $5 \mathrm{ml}$ of Brain Heart Infusion (BHI) Broth (Oxoid). The viable count of this suspension was calculated by spreading $100-\mu 1$ portions of 10 -fold dilutions (in BHI broth) of the suspension on to plates of blood agar and counting the number of colonies visible after incubation for $36 \mathrm{~h}$ at $37^{\circ} \mathrm{C}$ in an atmosphere containing $\mathrm{CO}_{2} 5 \% \mathrm{v} / \mathrm{v}$. Initial evaluation of the sensitivity of the PCR-immunoassay was performed with sterile distilled water, pooled sterile CSF or blood, each spiked with appropriate dilutions of the known suspension of $N$. meningitidis strain SD,
B:15:P1. Clinical specimens comprised $294 \mathrm{CSF}$ and 173 EDTA blood samples, obtained from patients suspected of suffering from meningitis. These were collected over a period of 9 months from the diagnostic microbiology and haematology laboratories at University Hospital, Nottingham. The clinical samples included 125 paired CSF/blood sets. Conventional microbiological analysis was performed by microscopic examination of CSF and culture of CSF and blood samples by standard techniques $[1,12]$.

\section{DNA extraction and PCR amplification}

Total DNA was released from all CSF samples by heating $50-\mu \mathrm{l}$ portions in $500-\mu \mathrm{l}$ microfuge tubes at $95^{\circ} \mathrm{C}$ for $15 \mathrm{~min}$, followed by centrifugation at $12000 \mathrm{~g}$ for $1 \mathrm{~min}$. DNA was extracted from $300-\mu 1$ portions of EDTA-treated blood with the InstaGene Whole Blood Kit (BioRad), used according to the manufacturer's instructions for the preparation of ligase chain reaction (LCR)-ready DNA. This procedure uses simple washing and centrifugation steps, takes $<45$ min to perform, and makes use of a matrix that binds to PCR inhibitors, thereby preventing DNA loss caused by irreversible DNA binding.

The PCR-immunoassay detection method was based on the use of a multiplex PCR that simultaneously detected a universal conserved sequence coding for bacterial 16S rRNA [11] and the porA gene which codes for the $N$. meningitidis class-1 outer membrane protein, PorA $[5,6]$. Custom synthesised oligonucleotide primers (Oswel, Southampton) used to generate dual-labelled porA and 16S rDNA products are listed in Table 1. The specificity of these primers has been demonstrated previously $[6,13]$.

PCRs were performed with Ready-To-Go PCR beads (Amersham Pharmacia Biotech) in final 25- $\mu$ l volumes containing $5 \mu \mathrm{l}$ of DNA extract and $1.5 \mathrm{pmol}$ of each of the four primers in Table 1. After initial trial experiments (see Results), each PCR comprised 35 cycles of $2 \mathrm{~min}$ at $95^{\circ} \mathrm{C}, 2 \mathrm{~min}$ at $55^{\circ} \mathrm{C}$ and $2 \mathrm{~min}$ at $72^{\circ} \mathrm{C}$, followed by $6 \mathrm{~min}$ at $72^{\circ} \mathrm{C}$. Parallel positive $(N$. meningitidis) and negative (distilled water) controls were included in each set of PCRs.

\section{PCR-immunoassay for detection of PCR products}

After completion of the PCR, $1 \mu 1$ of each reaction mix was added to $99 \mu \mathrm{l}$ of TBE buffer ( $89 \mathrm{mM}$ Tris, $89 \mathrm{mM}$

Table 1. Primers and labels used in the multiplex PCR

\begin{tabular}{|c|c|c|c|c|c|}
\hline Primer & Label & Sequence & Target & $\begin{array}{l}\text { Product size } \\
\text { (bp) }\end{array}$ & References \\
\hline X & 5'-triple-DNP & GGAATTCAAA $^{\mathrm{T}} /{ }_{\mathrm{G}}$ GAATTGACGGGGC & Conserved bacterial & 476 & {$[11,13]$} \\
\hline Y & $5^{\prime}-\mathrm{DIG}$ & CGGGATCCCAGGCCCGGGAACGTATTCAC & $16 \mathrm{~S}$ rDNA & & \\
\hline P1 & 5'-triple-DNP & GCGGCCGTTGCCGATGTCAGCC & N. meningitidis porA gene & 1100 & {$[5,6]$} \\
\hline $\mathrm{P} 2$ & $5^{\prime}$-biotin & GCGGCATTAATTTGAGTGTAGTTGCC & & & \\
\hline
\end{tabular}


boric acid, $2 \mathrm{mM}$ EDTA, $\mathrm{pH} 8.0$ ) and the 100- $\mu 1$ mixture was applied to a Clearview ${ }^{\mathrm{TM}}$ Immunoassay Detection Device (Unipath, Bedford). These prototype devices have been described in detail previously [11] but, in brief, consist of a small plastic enclosure $(3.5 \times 8.5 \times 0.4 \mathrm{~cm})$ holding a membrane and a sample application pad containing blue latex beads labelled with an anti-dinitrophenol (DNP) antibody. The membrane is coated with lines of anti-biotin antibody and anti-digoxigenin (DIG) antibody in separate result 'windows'. The labelled primers listed in Table 1 were designed to generate dual-labelled PCR products, i.e., a 16S rDNA product labelled with DNP and DIG, and a porA product labelled with DNP and biotin. In the presence of a specific dual-labelled endproduct, the blue latex beads (coated with anti-DNP) localise to either the anti-biotin or anti-DIG lines on the membrane, yielding an easy-to-read blue line as an end-point (Fig. 1). Results are obtained within 5 min of applying the diluted PCR mix to the application pad.

For evaluation purposes, the remaining $24-\mu 1$ portion of each PCR mix was analysed by conventional agarose gel electrophoresis following staining with ethidium bromide [14], and the results obtained were compared with those obtained by conventional culture techniques $[1,12]$ in the diagnostic microbiology laboratory.

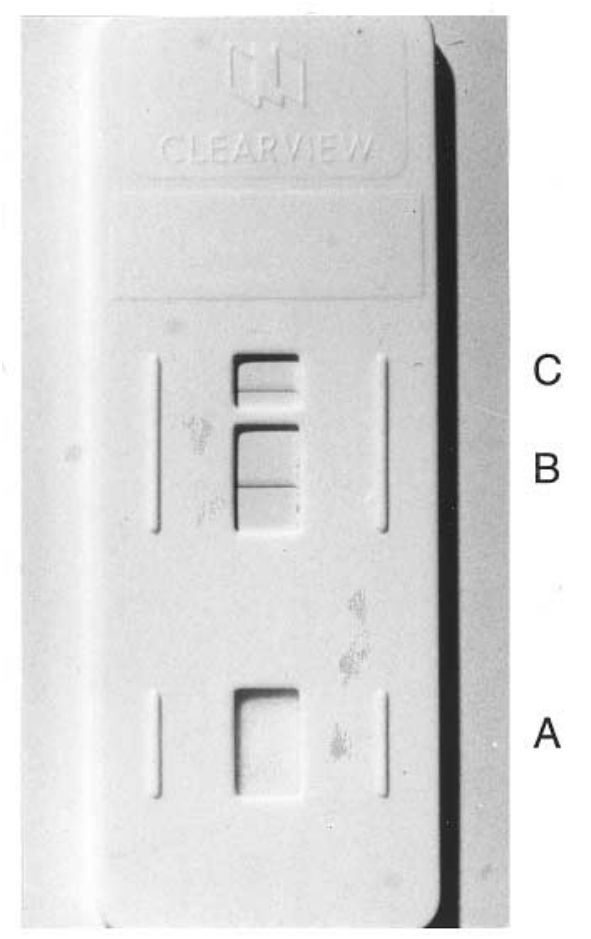

Fig. 1. Example of an immunoassay device showing a positive result for $N$. meningitidis. A, sample application window; B, first result window showing blue latex beads localised to the anti-biotin antibody (diagnostic of the presence of the amplified $N$. meningitidis porA gene); $\mathbf{C}$, second result window showing blue latex beads localised to the anti-DIG antibody (diagnostic of the presence of the amplified universal bacterial 16S rDNA sequence).

\section{Results}

\section{Optimisation of PCR conditions}

A range of primer concentrations and ratios (0.5$10 \mathrm{pmol}$ of each primer/reaction mix) and annealing temperatures $\left(50-70^{\circ} \mathrm{C}\right)$ were tested in initial trial experiments. Other amplification conditions were based on those used previously for the same sets of primers $[6,11]$. Addition of $\geqslant 7.5 \mathrm{pmol}$ of each primer to reaction mixes generated false-positive results in the immunoassay devices with negative control samples of pooled CSF taken from patients for whom there was no suspicion of meningitis. This phenomenon has been reported previously [11] and may be caused by the formation of primer-dimer combinations at high primer concentrations. In addition, it was observed that falsenegative results were obtained with CSF samples spiked with $7 \times 10^{6} \mathrm{cfu} / \mathrm{ml}$ of the control strain of $N$. meningitidis when the PCR annealing temperature was raised above $60^{\circ} \mathrm{C}$. Specific and reproducible results were obtained with $1.5 \mathrm{pmol}$ of each of the four primers and an annealing temperature of $55^{\circ} \mathrm{C}$. These conditions were then used to test the sensitivity of the system and for subsequent analysis of the 467 clinical samples included in the study.

\section{Sensitivity of the PCR-immunoassay}

The sensitivity of the procedure was evaluated with pooled CSF or peripheral blood, taken from patients for whom there was no suspicion of meningococcal disease, spiked with 10-fold dilutions of a known culture of the control strain of $N$. meningitidis. Duplicate DNA extractions were made at each dilution, followed by duplicate PCRs. When examined by agarose gel electrophoresis and ethidium bromide staining, the predicted PCR products of $479 \mathrm{bp}$ (16S rDNA) and $1.1 \mathrm{~kb}$ (porA) were visualised from CSF and blood samples containing $(\geqslant 3-5) \times 10^{3} \mathrm{cfu} / \mathrm{ml}$, equivalent to $\geqslant 10-30 \mathrm{cfu}$ in the $5-\mu 1$ portion of DNA extract added to each PCR (Fig. 2). In comparison, the PCR-immunoassay devices were one $\log _{10}$ dilution more sensitive, giving positive results (as shown in Fig. 1) from CSF and blood samples containing ( $\geqslant 3-5)$ $\times 10^{2} \mathrm{cfu} / \mathrm{ml}$, equivalent to $1-3 \mathrm{cfu}$ in the $5-\mu 1$ portion of DNA extract added to each PCR.

\section{Use of the PCR-immunoassay to detect bacteria in clinical samples of CSF and blood}

When the 294 CSF samples were examined by conventional methodology, 25 CSF samples were reported by the routine diagnostic laboratory to contain bacteria, comprising $N$. meningitidis (11 samples), Streptococcus pneumoniae (4), S. epidermidis (4), S. aureus (2), group B streptococci (2), Pseudomonas aeruginosa (1) and Klebsiella aerogenes (1). The PCRimmunoassay system detected bacterial 16S rDNA in 29 of the 294 CSF samples, including all those reported positive in the routine diagnostic laboratory, 


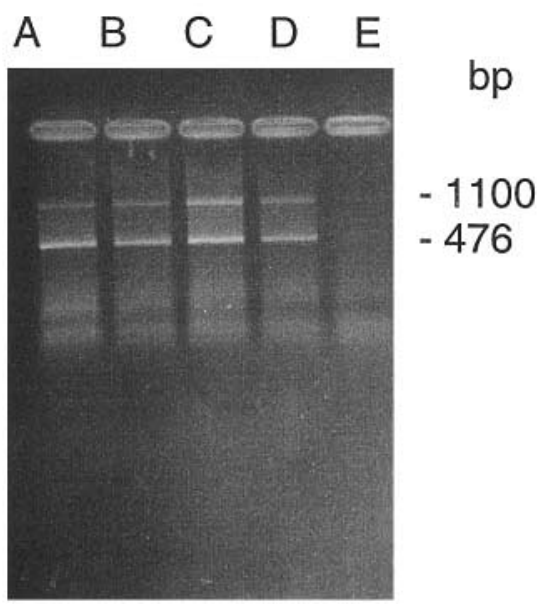

Fig. 2. Example of the sensitivity of detection of specific PCR products by agarose gel electrophoresis and staining with ethidium bromide. Each lane contains the products of an identical PCR (as described in Materials and methods) derived from peripheral blood spiked with dilutions of a known suspension of $N$. meningitidis strain SD, B:15:P1. A, $3 \times 10^{6} \mathrm{cfu} / \mathrm{ml} ; \quad$ B, $3 \times 10^{5}$ $\mathrm{cfu} / \mathrm{ml} ; \quad \mathbf{C}, \quad 3 \times 10^{4} \mathrm{cfu} / \mathrm{ml} ; \quad$ D,$\quad 3 \times 10^{3} \mathrm{cfu} / \mathrm{ml} ; \quad \mathbf{E}$ ， $3 \times 10^{2} \mathrm{cfu} / \mathrm{ml}$.

plus four additional samples that were found to be positive by PCR for both bacterial $16 \mathrm{~S}$ rDNA and the porA gene of $N$. meningitidis. The $11 \mathrm{CSF}$ samples reported as containing $N$. meningitidis by conventional methodology were also positive for $N$. meningitidis by the PCR-immunoassay. All negative PCR-immunoassay results correlated with negative results following Gram's stain and bacterial culture. These results are summarised in Table 2.

Of 173 peripheral blood samples examined, the PCRimmunoassay detected bacterial 16S rDNA in 18 blood samples, 14 of which were also positive for $N$. meningitidis. In comparison, only 10 samples were reported positive for $N$. meningitidis by conventional methodology (Table 2). Again, all negative PCRimmunoassay results correlated with those obtained by conventional methodology.

Of the 125 paired sets of CSF and peripheral blood that were tested, six paired sets were positive (CSF and blood) for $N$. meningitidis by both conventional analysis and the PCR-immunoassay. Three more CSF samples were positive for $N$. meningitidis by both methods, although the corresponding paired blood samples were negative. In two further cases, CSF samples were found to be positive for $N$. meningitidis by PCR-immunoassay, but were reported negative by conventional methodology. In these two cases, the corresponding paired blood samples were reported positive for $N$. meningitidis by both PCR-immunoassay and conventional methodology. These results are summarised in Table 3.

\section{Discussion}

PCR techniques have now been used in many research laboratories world-wide for the direct detection of specific bacteria and viruses in clinical specimens (including blood, CSF and tissues), and PCR is now used routinely by the PHLS Meningococcal Reference Unit to detect meningococcal DNA in samples from patients who are culture-negative because of previous antibiotic treatment [9]. It has been shown that PCR can be used successfully to detect meningococcal DNA in specimens of peripheral blood if the sensitivity of PCR product detection is increased with an ELISA technique [3]. It has been estimated that wide application of this technique might increase the number of cases of meningococcal disease with a confirmed diagnosis by as much as $60 \%$, with no requirement to obtain a CSF sample [3]. However, although the PCR technique is, in itself, very simple to complete within $2-3 \mathrm{~h}$, the need for an initial time-consuming DNA extraction procedure, usually based on the Boom method [15], from blood buffy coat layer or serum, coupled with technically demanding post-PCR electro-

Table 3. Summary of results obtained by conventional microbiological analysis and the PCR-immunassay technique with 125 paired sets of CSF and peripheral blood

\begin{tabular}{|c|c|c|c|}
\hline \multicolumn{2}{|c|}{ Result combination } & \multicolumn{2}{|c|}{ Number positive for $N$. meningitidis } \\
\hline $\mathrm{CSF}$ & blood & $\begin{array}{l}\text { Conventional } \\
\text { microbiological analysis }\end{array}$ & $\begin{array}{c}\text { PCR- } \\
\text { immunoassay }\end{array}$ \\
\hline+ & + & 6 & 8 \\
\hline+ & - & 3 & 3 \\
\hline- & + & $2^{*}$ & 0 \\
\hline- & - & 114 & 114 \\
\hline
\end{tabular}

+ , Positive result; - , negative result.

*These two samples were CSF-positive, blood-positive by the PCRimmunoassay.

Table 2. Summary of results obtained with CSF and peripheral blood samples by conventional microbiological analysis and the PCR-immunoassay technique

\begin{tabular}{lcc}
\hline Sample type and result & $\begin{array}{l}\text { Positive by conventional } \\
\text { microbiological analysis }\end{array}$ & Positive by PCR-immunoassay \\
\hline CSF $(\mathrm{n}=294)$ & & $29^{*}$ \\
any bacteria & 25 & $15^{*}$ \\
$N$. meningitidis & 11 & $18^{*}$ \\
Peripheral blood $(\mathrm{n}=173)$ & 14 & $14^{*}$ \\
$\quad$ any bacteria & 10 & \\
$N$. meningitidis & & \\
\hline
\end{tabular}

\footnotetext{
*Including all those detected by conventional microbiological analysis (routine culture and Gram's
} stain). 
phoresis or ELISA detection procedures, has prevented the widespread acceptance of PCR for routine identification of meningococcal disease by diagnostic laboratories.

To circumvent the first problem of DNA extraction, the work reported in this paper demonstrated that the commercially available InstaGene Kit provided a simple method for extraction of bacterial DNA from peripheral blood in $<45 \mathrm{~min}$. The kit is stated by the manufacturers to work regardless of the blood anticoagulant (heparin, EDTA or citrate) used, and no tube transfers are necessary, thereby reducing the scope for error or sample loss. In combination with the sensitive immunoassay detection procedure for PCR products (see below), a level of sensitivity nearing the theoretical limit of detection (1 cfu) was achieved, although it is probable that a number of non-viable cells were also contained within the suspension of meningococci used to spike the samples being examined. For extraction of bacterial DNA from CSF, a simple heating procedure followed by a short centrifugation step, was found to yield equivalent sensitivity.

Previous studies assessing the use of PCR-based strategies for the diagnosis of meningococcal meningitis in blood and CSF [e.g., 3, 5-8] have resolved the PCR amplification products on agarose gels [5] or have relied on detection and identification by ELISA [3] or DNA sequencing [7,8]. The present study investigated the possibility of making the PCR technique more accessible to routine diagnostic laboratories by the use of a simple and cheap immunoassay device for detection of PCR products. For evaluation purposes, amplification of the specific $N$. meningitidis porA gene was combined in a multiplex PCR assay with detection of a 'universal' bacterial 16S rDNA sequence, followed by rapid detection of the specific PCR products by the immunoassay method. When the PCR-immunoassay was applied to specimens received in a routine laboratory as part of the normal diagnostic microbiology service, it was found to be one $\log _{10}$-fold more sensitive than detection of PCR products on agarose gels, and more positive results were detected by the PCR-immunoassay system than by conventional microbiological analysis. It is difficult to be certain whether or not the 'additional' PCR-positive results obtained were false-positives since, by definition, meningococci or other bacteria were not identified by conventional methodology. However, such samples were repeatedly positive in the multiplex PCR for both the bacterial $16 \mathrm{~S}$ rDNA sequence and the $N$. meningitidis porA gene, a dual event that might be expected to occur at a very low frequency by chance contamination alone, particularly as no instances of a porA-positive and a 16S rDNA-negative combination were detected. The greater sensitivity of the PCR-immunoassay was also indicated by the paired CSF/blood sets in which the PCR-immunoassay detected meningococci in both CSF and blood, while conventional methodology detected meningococci only in the blood samples. No falsenegative results were observed (i.e., negative by PCRimmunoassay, but positive by conventional methodology).

The PCR-immunoassay devices are not yet commercially available but, as described elsewhere [10,11], have the potential to be used in any application requiring the rapid detection of specific PCR products. The only requirement is for a set of appropriately labelled specific primers for each individual application. The combined DNA extraction and PCR-immunoassay techniques described in this paper have the potential to improve the ability of routine microbiology laboratories to diagnose meningococcal meningitis rapidly at the local level. The introduction of a rapid, specific and sensitive PCR test for meningococcal meningitis that can be used with peripheral blood will represent a significant and timely advance in the local diagnosis of meningococcal disease.

This work was supported by a grant awarded to K. J. T. by the Meningitis Research Foundation. We are indebted to D. C. S. Talbot and Unipath Ltd for the supply of prototype Clearview immunoassay detection devices, and to the staff of the Nottingham Public Health Laboratory and the Haematology Laboratory at University Hospital, Nottingham, for assistance with the collection of samples.

\section{References}

1. Bohr V, Rasmussen N, Hansen B et al. 875 cases of bacterial meningitis: diagnostic procedures and the impact of preadmission antibiotic therapy. Part III of a three-part series. $J$ Infect 1983; 7: 193-202.

2. Richards PG, Towu-Aghantse E. Dangers of lumbar puncture. BMJ 1986; 292: 605-606.

3. Newcombe J, Cartwright K, Palmer WH, McFadden J. PCR of peripheral blood for diagnosis of meningococcal disease. $J$ Clin Microbiol 1996; 34: 1637-1640.

4. Cartwright K, Reilly S, White D, Stuart J. Early treatment with parenteral penicillin in meningococcal disease. BMJ 1992; 305: $143-147$.

5. Saunders NB, Zollinger WD, Rao VB. A rapid and sensitive PCR strategy employed for amplification and sequencing of porA from a single colony-forming unit of Neisseria meningitidis. Gene 1993; 137: 153-162.

6. Saunders NB, Shoemaker DR, Brandt BL, Zollinger WD. Confirmation of suspicious cases of meningococcal meningitis by PCR and enzyme-linked immunosorbent assay. $J$ Clin Microbiol 1997; 35: 3215-3219.

7. Kotilainen $\mathrm{P}$, Jalava J, Meurman $\mathrm{O}$ et al. Diagnosis of meningococcal meningitis by broad-range bacterial PCR with cerebrospinal fluid. J Clin Microbiol 1998; 36: 2205-2209.

8. Hall LMC, Duke B, Urwin G. An approach to the identification of the pathogens of bacterial meningitis by the polymerase chain reaction. Eur J Clin Microbiol Infect Dis 1995; 14: 1090-1094.

9. Kaczmarski EB, Ragunathan PL, Marsh J, Gray SJ, Guiver M. Creating a national service for the diagnosis of meningococcal disease by polymerase chain reaction. Commun Dis Public Health 1998; 1: 54-56.

10. Towner KJ, Talbot DCS, Curran R, Webster CA, Humphreys H. Development and evaluation of a PCR-based immunoassay for the rapid detection of methicillin-resistant Staphylococcus aureus. J Med Microbiol 1998; 47: 607-613.

11. Curran R, Talbot DCS, Towner KJ. A rapid immunoassay method for the direct detection of PCR products: application to detection of TEM-1 $\beta$-lactamase genes. J Med Microbiol 1996; 45: $76-78$.

12. Dunbar SA, Eason RA, Musher DM, Clarridge JE. Microscopic examination and broth culture of cerebrospinal fluid in 
diagnosis of meningitis. J Clin Microbiol 1998; 36: $1617-$ 1620.

13. Geha DJ, Uhl JR, Gustaferro CA, Persing DH. Multiplex PCR for identification of methicillin-resistant staphylococci in the clinical laboratory. J Clin Microbiol 1994; 32: 1768-1772.

14. Maniatis T, Fritsch EF, Sambrook J (eds). Molecular cloning: a laboratory manual. Cold Spring Harbor, NY, Cold Spring Harbor Laboratory. 1982: 156-163.

15. Boom R, Sol CJA, Salimans MMM, Jansen CL, Wertheim-van Dillen PME, van der Noordaa J. Rapid and simple method for purification of nucleic acids. J Clin Microbiol 1990; 28: 495-503. 